\title{
Reconstruction of Mandibular Defects
}

\author{
Harvey Chim, M.D., ${ }^{1}$ Christopher J. Salgado, M.D. ${ }^{2}$ Samir Mardini, M.D., 3 \\ and Hung-Chi Chen, M.D., F.A.C.S. ${ }^{4}$
}

\section{ABSTRACT}

Defects requiring reconstruction in the mandible are commonly encountered and may result from resection of benign or malignant lesions, trauma, or osteoradionecrosis. Mandibular defects can be classified according to location and extent, as well as involvement of mucosa, skin, and tongue. Vascularized bone flaps, in general, provide the best functional and aesthetic outcome, with the fibula flap remaining the gold standard for mandible reconstruction. In this review, we discuss classification and approach to reconstruction of mandibular defects. We also elaborate upon four commonly used free osteocutaneous flaps, inclusive of fibula, iliac crest, scapula, and radial forearm. Finally, we discuss indications and use of osseointegrated implants as well as recent advances in mandibular reconstruction.

KEYWORDS: Bone flap, condyle, fibular flap, mandible, osseointegrated implant, osteocutaneous flap

Continuing advances in mandibular reconstruction have greatly improved functional and aesthetic outcomes for patients. Outcomes from free vascularized bone flaps have proved markedly superior to those obtained from use of nonvascularized options such as reconstruction plates and bone grafts. The free fibula flap continues to remain the gold standard for mandibular reconstruction against which other modalities are compared.

The mandible serves several important functions in the head and neck, which can be restored to nearnormality with the use of vascularized bone flaps. It provides a stable platform for the oral cavity and also a structure to which muscles attach. Most importantly, it allows mastication by providing a stable counterpoint to the maxilla and serving as a base for attachment of dentition. It facilitates speech, swallowing, and breath- ing by maintaining space within the oral cavity and allowing the tongue to function. It also serves an aesthetic function, defining the projection of the lower third of the face.

\section{ANATOMY OF THE MANDIBLE}

The mandible is a U-shaped bone that articulates with the skull base through two unique temporomandibular joints $(\mathrm{TMJ} s)$, which allow smooth and coordinated mouth opening. The TMJ is a diarthrodial joint, consisting of two bones articulating in a discontinuous fashion allowing freedom of movement dictated by muscles and limited by ligamentous attachments. The TMJ is also lined on its internal aspect by synovium, which secretes synovial fluid, serving both as a lubricant and a nutrition source for joint structures.

\footnotetext{
${ }^{1}$ Department of Plastic Surgery, Case Western Reserve University, Cleveland, Ohio; ${ }^{2}$ Division of Plastic Surgery, Department of Surgery, University of Miami, Miami, Florida; ${ }^{3}$ Division of Plastic Surgery, Department of Surgery, Mayo Clinic, Rochester, Minnesota; ${ }^{4}$ Department of Plastic Surgery, E-Da Hospital/I-Shou University, Kaoshiung County, Taiwan.

Address for correspondence and reprint requests: Christopher J. Salgado, M.D., Division of Plastic Surgery, Department of Surgery, University of Miami Miller School of Medicine, Holtz Children's Center - ET3019, 1611 NW 12th Avenue, Miami, FL 33136
}

(e-mail: salgado_plastics@hotmail.com).

Advances in Head and Neck Reconstruction, Part I; Guest Editors, Samir Mardini, M.D., Christopher J. Salgado, M.D., and Hung-Chi Chen, M.D., F.A.C.S.

Semin Plast Surg 2010;24:188-197. Copyright (C) 2010 by Thieme Medical Publishers, Inc., 333 Seventh Avenue, New York, NY 10001, USA. Tel: +1(212) 584-4662.

DOI: http://dx.doi.org/10.1055/s-0030-1255336.

ISSN 1535-2188. 
The TMJ is termed a ginglymoarthrodial joint as it is functionally divided into two compartments, separated by an articular disk. ${ }^{1}$ The superior compartment allows sliding or translational movements and is termed artbrodial, and the inferior compartment allows hinge motion or rotation and is therefore termed ginglymoid. The TMJ is one of the only synovial joints in the body with an articular disk. The inferior compartment functions in initial mouth opening from an interincisal distance of 0 to $20 \mathrm{~mm}$. Subsequently, the superior compartment allows further translational movement to full mouth opening, to an interincisal distance of $50 \mathrm{~mm}$. In this arthrodial movement, the entire apparatus consisting of the condylar head and articular disk translates in relation to the mandibular fossa of the temporal bone.

On its superior aspect, the mandible bears 16 permanent teeth anchored into the alveolus, consisting of 1 central incisor, 1 lateral incisor, 1 canine, 2 premolars, and 3 molars on each side. These facilitate mastication and can be restored with the use of osseointegrated implants after mandibular reconstruction.

Mandibular movement is provided largely by the four muscles of mastication, which consist of the masseter, temporalis, medial pterygoid, and lateral pterygoid. These muscles are all innervated by the mandibular division of the trigeminal nerve. The lateral pterygoid serves to open the mouth and protrude the mandible, whereas the other three muscles close the mouth and elevate the mandible. Preserving the attachments of these muscles where possible during the resection prevents an imbalance in forces, which can result in pain and altered mouth opening, particularly after radiation therapy. ${ }^{2}$

\section{TYPE OF DEFECT AND APPROACH TO RECONSTRUCTION}

Mandibular defects can generally be considered by their location and extent and can be divided into defects involving the anterior mandible, lateral mandible, and ramus/condyle. The Jewer classification provides an aid in classifying mandibular defects ${ }^{3}$ and reflects the complexity of the reconstructive problem. Central defects including both canines are designated "C," and lateral segments that exclude the condyle are designated "L." When the condyle is resected together with the lateral mandible, the defect is designated " $\mathrm{H}$," or hemimandibular. Eight permutations of these capital letters-C, L, $\mathrm{H}, \mathrm{LC}, \mathrm{HC}, \mathrm{LCL}, \mathrm{HCL}$, and HH-are encountered for mandibular defects. The significance of this is that a lateral defect can be reconstructed with a straight segment of bone, whereas a central defect would require osteotomies. The classification was modified ${ }^{4}$ to include a soft tissue description as well, with " $\mathrm{t}$ " representing a significant tongue defect, " $\mathrm{m}$ " a mucosal defect, and "s" an external skin defect. As an example, reconstruction of an LCL-mt defect would be much more complex and require more volume than would a simple $\mathrm{L}$ defect.

Anterior mandibular (C) defects will typically constitute an absolute indication for reconstruction using vascularized bone. Due to multiple osteotomies required to contour the bone, fibula should be considered the first choice for reconstruction of anterior or large defects., Other modalities of reconstruction have resulted in poor outcomes.

Some centers will reconstruct lateral (L) defects with vascularized bone, ${ }^{6,7}$ whereas others would prefer to use soft tissue flaps with or without plates for reconstruction. In general, reconstruction with vascularized bone has led to better outcomes, with complication rates ranging from 0 to $18 \%,{ }^{6,7}$ and an increased number of patients returning to a regular, unrestricted diet (47 to 65\%). ${ }^{6,7}$

Reconstruction with plates has resulted in variable outcomes, with reported complication rates ranging from 7 to $69 \% .^{8-12}$ Plate exposure is one of the most common complications ${ }^{8,12}$ and is often the reason for secondary salvage surgery with a vascularized bone flap. Low success rates of plate-only reconstruction have been reported, ranging from $34 \%$ at 6 months $^{13}$ to $64 \%$ at 1-year follow-up. ${ }^{14}$ Plate viability was further reduced by radiation therapy. In our experience, plate reconstruction alone is prone to failure. Not only does the plate become exposed in many instances, leading to complications such as infection and orocutaneous fistulae, but also plate failure is a serious complication that necessitates a second salvage surgery.

Nonvascularized bone grafts (NBGs), such as from iliac crest, are another option for reconstruction of small pure lateral mandibular defects. These are less often used nowadays, however, particularly in centers with microvascular expertise. NBGs are associated with a high rate of complications ${ }^{15}$ and are prone to undergoing osteoradionecrosis after radiation therapy. A direct comparison of NBGs and vascularized bone flaps (VBFs) in 75 consecutive reconstructions by Foster et $\mathrm{al}^{16}$ reported a rate of bony union in $69 \%$ of NBGs and $96 \%$ of VBFs $(p<0.001)$. Hence, NBG may best be suited for reconstruction of small $\mathrm{L}$ defects $(<6 \mathrm{~cm})$ in patients who will not tolerate major surgery or in centers without microsurgical expertise. An example is shown in Fig. 1, where a nonvascularized rib segment was used to reconstruct an $\mathrm{H}$ defect. Deviation of the mandibular midline to the left has already occurred, and this is a scenario where the patient would be unable to masticate, and where not only has the plate failed but the bone graft would ultimately fail as well.

An argument for using soft tissue flaps alone instead of VBF in reconstruction of posterolateral defects was presented by Mosahebi et al. ${ }^{17}$ Often, the skin paddle with a fibula flap is inadequate for reconstruction of large posterosuperior soft tissue and intraoral defects, 


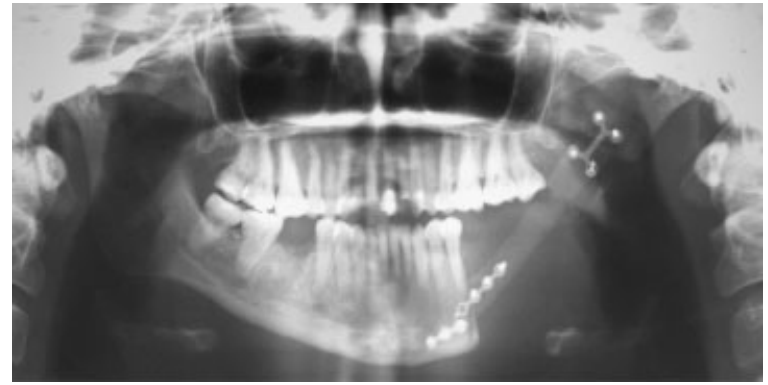

Figure 1 Nonvascularized rib was used to bridge a left hemimandibulectomy defect in this patient. Early deviation of the mandibular midline to the left is seen on this Panorex. Ultimately, this form of reconstruction is doomed to failure, with the patient unable to masticate, and potential for failure of the bone graft, particularly after radiation therapy.

as well as through-and-through defects that may require more than one skin paddle for reconstruction. Also, the stiffness of the skin and subcutaneous tissue overlying the fibula does not facilitate molding of the skin paddle into complex three-dimensional defects. The fibula flap does not provide sufficient bulk to fill defects in resections extending superiorly to the glenoid fossa or to the temporal bone.

Soft tissue flaps alone, such as anterolateral thigh (ALT), gracilis, rectus, and latissimus dorsi, have been used successfully in reconstruction of posterolateral defects, ${ }^{17,18}$ with outcomes not statistically different than those obtained with VBF. However, postoperative occlusion was found to be better in one study when vascularized bone was compared with soft tissue flaps for reconstruction of posterior mandibular defects. ${ }^{18} \mathrm{In}$ the same study, however, $45 \%$ of patients were able to tolerate a regular diet despite a suboptimal occlusion. A study by King et al, ${ }^{19}$ however, found that VBF had statistically significant superior functional and aesthetic scores for diet, oral competence and speech, public dining, and midline symmetry compared with those of soft tissue flaps alone for reconstruction of posterior mandible defects.

Though advocates for use of soft tissue flaps alone for reconstruction of posterolateral defects present compelling arguments, some centers routinely reconstruct these defects with multiple free flaps. Wei et $\mathrm{al}^{20,21}$ have routinely used combinations such as fibula-ALT, fibularadial forearm, or iliac crest-tensor fasciae latae flaps with excellent results. Another less technically demanding option is the fibula-pedicled pectoralis major combination. ${ }^{22}$ An argument against the use of soft tissue flaps alone for reconstruction of $\mathrm{L}$ - and $\mathrm{H}$-type defects is that the imbalance of forces on the remaining native mandible results in a deviation to the resected side leading to eventual wear, loss of function, and caries. ${ }^{9}$

In patients who may not be fit for extensive surgery involving free tissue transfer due to comorbidities, regional soft tissue flaps such as pedicled pectoralis major or cervicodeltopectoral can be used for reconstruction of $\mathrm{L}$ and $\mathrm{H}$ defects. In practice, it was found in a study by Deleyiannis et $\mathrm{al}^{23,24}$ that advanced age ( $>70$ years), moderate or severe comorbidity, and tumor involvement of the base of the tongue were factors that favored use of regional flaps.

In general, it is clear that, if the patient is fit for major surgery, reconstruction of $\mathrm{H}$ - and L-type defects with VBF is preferred. ${ }^{19,25}$ However, soft tissue only reconstruction is an acceptable alternative with adequate long-term outcomes. Plate reconstruction and regional flaps should be reserved for patients unfit for major surgery, patients with a poor prognosis, or for salvage surgeries.

\section{CONDYLE RECONSTRUCTION}

Reconstruction of the condyle aims to preserve sufficient interincisal opening and also to preserve balance of the mandible articulating against the skull base to stabilize the muscles of mastication and preserve preoperative occlusion. Where possible, the condyle should be preserved during the resection. Otherwise, the condyle can also be affixed as a nonvascularized graft to the end of the reconstruction. Hidalgo ${ }^{4,26}$ showed that nonvascularized condyles transected at the midramus level or higher and subsequently attached to the reconstructed neomandible survived more than a decade. Other options include placing the end of the bone flap into the fossa, interposing periosteum ${ }^{27}$ or temporalis muscle-fascia. ${ }^{28}$ The aim in this case is to achieve a painless gap arthroplasty at the TMJ. Surprisingly, many patients do remarkably well, being pain-free and able to chew food.

Costochondral rib grafts have been used for reconstruction of the condyle. ${ }^{29,30}$ In juveniles, the graft will grow with the native mandible. Good results have been reported, with one study reporting an interincisal opening of at least $30 \mathrm{~mm}$ in all patients. ${ }^{29}$ A pure soft tissue reconstruction has also been used successfully, without reconstruction of the mandible. ${ }^{18,31}$ Importantly, adequate soft tissue as a filler in the TMJ both reduces drift of the remaining mandible toward the side of the resection and camouflages the cut edge of the remaining mandible. ${ }^{18,32}$ Criticisms of not reconstructing the condyle are that this relies on the contralateral TMJ to maintain adequate stability and movement of the mandible, leading to inevitable deviation of the mandible to the nonreconstructed side and subsequent malocclusion. ${ }^{9}$

\section{COMMONLY USED FREE FLAPS}

\section{Fibula Flap}

The fibula provides the best option for mandible reconstruction. It provides a long segment of bone, up to 
$25 \mathrm{~cm}$ in length, that can tolerate multiple osteotomies without compromising its blood supply. ${ }^{33}$ It has a sizeable $(2$ to $3 \mathrm{~mm})$ and lengthy $(15 \mathrm{~cm})$ pedicle based on the peroneal artery and its venae comitantes that is sufficient in most defects. It is usually harvested with an accompanying skin paddle (Fig. 2) and can also be harvested with flexor hallucis longus ${ }^{34}$ or soleus muscle ${ }^{35}$ to fill soft tissue defects. The skin paddle is reliably

A
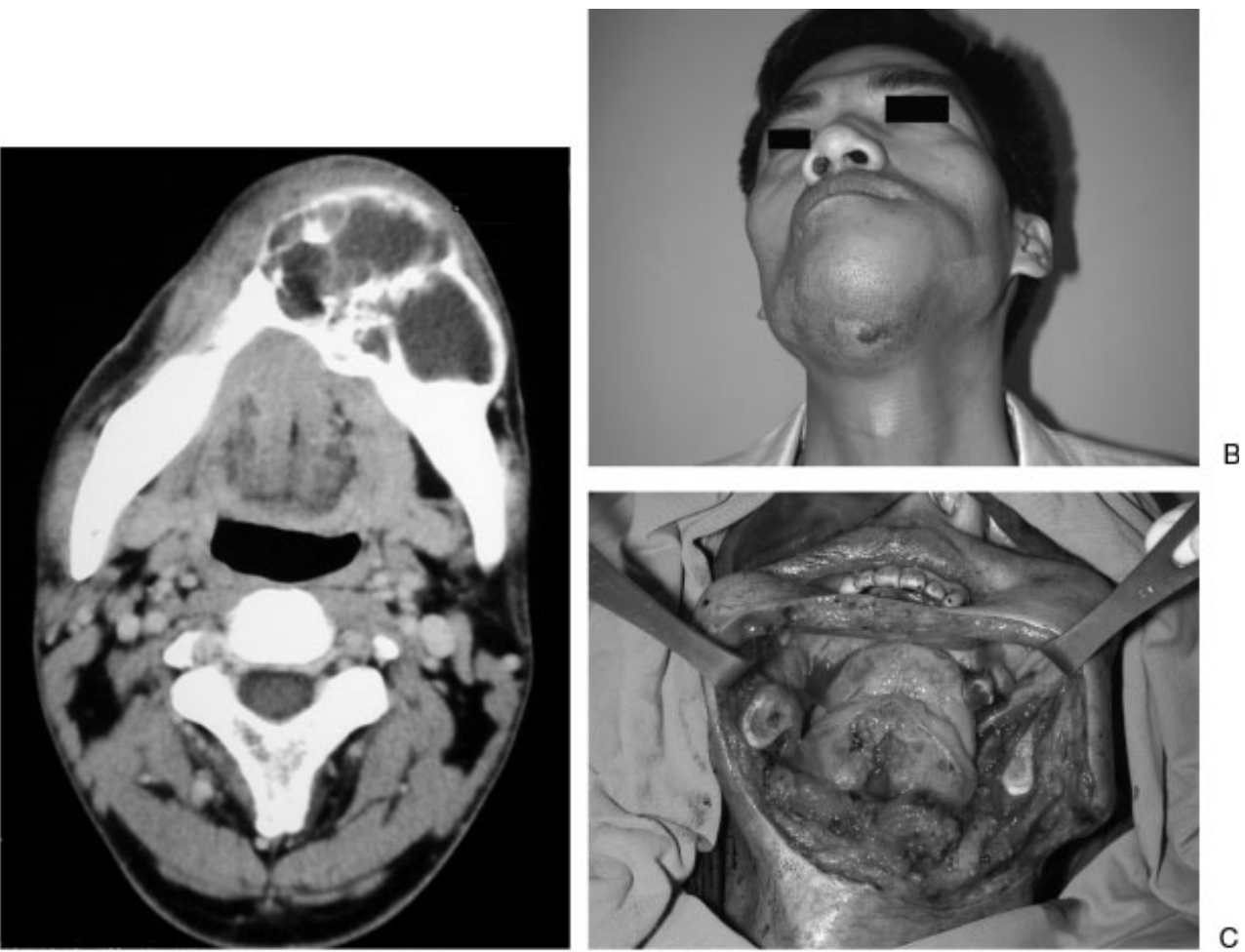

D
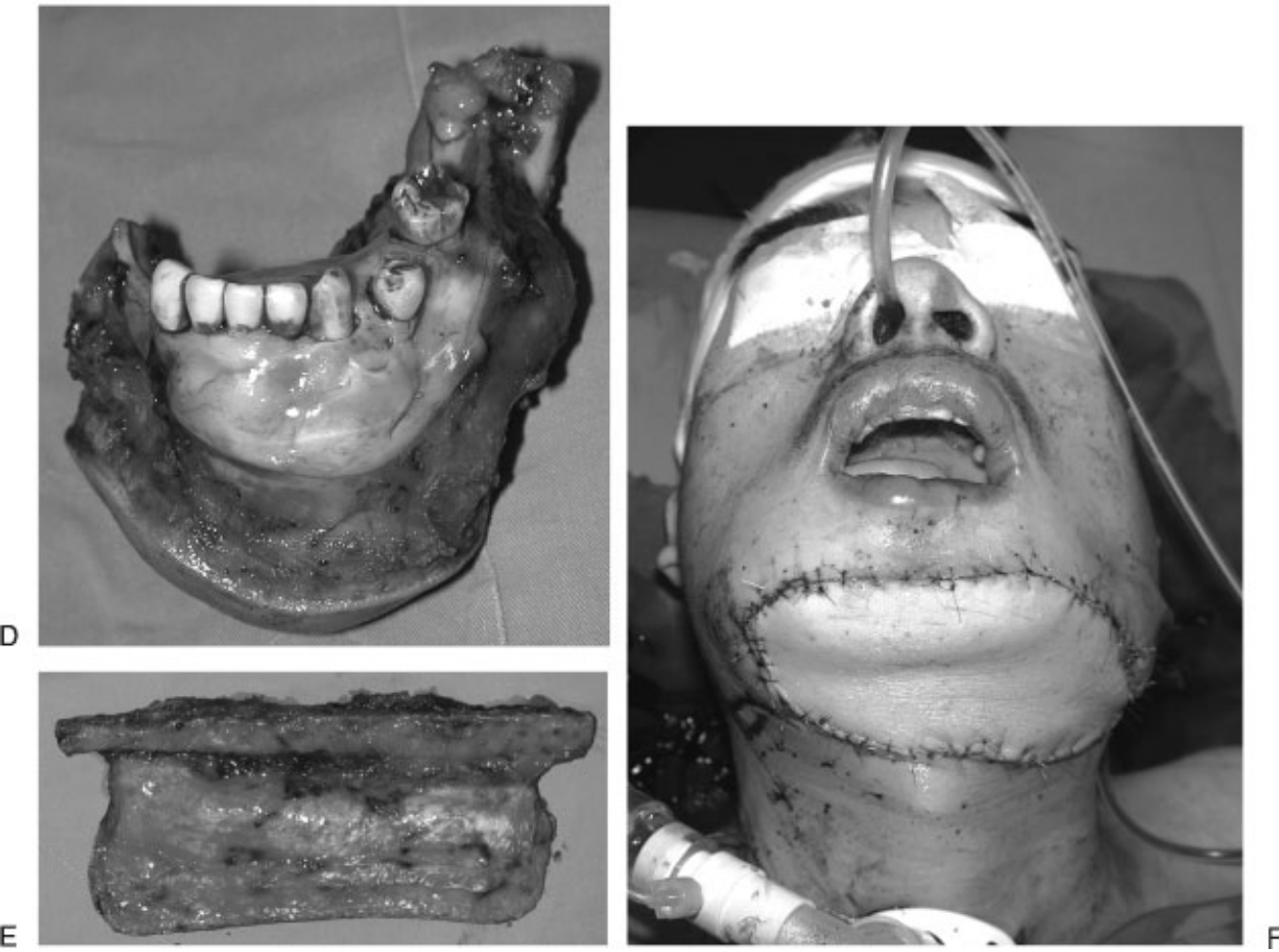

Figure 2 A large left CL-ms mandibular defect with involvement of floor of mouth and external skin was reconstructed using a free fibula flap. (A) Preoperative CT showing multicystic ameloblastoma involving left mandible, with gross erosion through external bony cortices. (B) Preoperative view showing erosion through skin over the chin. (C) Intraoperative defect. (D) Resected specimen. (E) Fibula flap after harvest. (F) Final result at closure. 
vascularized by septocutaneous perforators from the peroneal artery in 90 to $95 \%$ of cases. In a small subset of patients, musculocutaneous perforators have been found to originate from the peroneal artery, posterior tibial artery, or tibioperoneal trunk, necessitating a second set of microvascular anastomoses for preservation of the skin paddle. ${ }^{36}$ Another major advantage of the fibula flap is the ability to use a two-team approach, where the resecting and reconstructive team are able to work simultaneously, as the fibula is far from the head and neck. Reinnervation of free fibula flaps is possible, using the lateral cutaneous sural nerve as the target for neurotization. ${ }^{37,38}$

The reliability and viability of mandibular defects reconstructed with vascularized fibula has been shown more than a decade out from surgery by Hidalgo et al, ${ }^{4}$ with $70 \%$ of patients tolerating a regular diet, maintenance of good aesthetic results, and maintenance of good bone height (92 to 93\%).

Donor site morbidity from fibula flap harvest is slight, with main issues being pain on ambulation and ankle instability. A majority of patients (ranging from 72 to $76 \%$ ) were pain-free on ambulation. ${ }^{39,40}$ As a caveat, whereas function was preserved with fibula harvest, Bodde et al found that restoration of gait was not complete while walking at high velocity or while performing complicated actions. ${ }^{41}$ Early complications that can be prevented through meticulous technique include skin graft loss, wound dehiscence, and compartment syndrome from excessively tight primary closure of the donor site. Late complications such as weakness of great toe flexion can also be prevented by preservation of the neurovascular supply to the flexor hallucis longus. ${ }^{41,42} \mathrm{By}$ ensuring that a sufficient segment of distal fibula is preserved, problems with ankle instability and pain can be prevented.

Several technical refinements help in maximizing the reconstruction. A drawback of fibula for mandibular reconstruction is its limited height, ${ }^{43}$ which does not allow both contouring of the inferior mandibular margin and restoring sufficient alveolar height for dental implants. One solution is to inset the fibula construct in a double-barreled fashion, ${ }^{44,45}$ greatly increasing the height of the neomandible. This is particularly useful for reconstruction of anterior (C) defects. The fibula can also be placed more superiorly, around 10 to $15 \mathrm{~mm}$ inferior to the occlusal plane, to provide sufficient bone height for placement of implants. ${ }^{45}$ The inferior border may be reconstructed with a supplementary $2.4-\mathrm{mm}$ reconstruction plate to restore lower facial projection. Vertical distraction osteogenesis can also be applied secondarily to gain adequate alveolar height for osseointegrated implants, using a horizontal osteotomy. ${ }^{45-47}$

The role of preoperative angiography remains controversial. It has a definite use in patients with known peripheral vascular disease, previous leg trauma, or pre- vious surgery. ${ }^{48}$ Noninvasive modalities such as magnetic resonance angiography ${ }^{49}$ and computed tomography (CT) angiography ${ }^{50}$ have reduced the invasiveness of angiography but are disadvantaged by the cost of routine studies. Some would advocate preoperative angiograms for all patients ${ }^{51}$ due to its high positive predictive value and sensitivity in detecting vascular aberrations; however, others believe that this is unnecessary. ${ }^{52}$ The decision for routine preoperative angiography would ultimately depend on one's preference and practice.

\section{Iliac Crest Osteocutaneous Flap}

The iliac crest provides a large piece of curved corticocancellous bone, measuring 6 to $16 \mathrm{~cm}$ in length. It has a natural curvature that complements the curve of the lateral, and sometimes anterior, mandible and can be placed accordingly to fill defects. The flap is based off the deep circumflex iliac artery (DCIA), which arises from the lateral aspect of the external iliac artery, and can be harvested with its overlying skin, supplied through cutaneous perforators. When an osteocutaneous flap is harvested, a cuff of oblique and transversalis muscles must be included to protect the deep circumflex iliac vessels and musculocutaneous perforators, with the muscle cuff harvested in continuity with the overlying skin island. The diameter of the DCIA is in the range 2 to $3 \mathrm{~mm}$, and the length of the pedicle from the anterosuperior iliac spine to its junction at the external iliac artery is around 5 to $7 \mathrm{~cm}^{53}$

Advantages with use of the DCIA flap include a bone height that is often greater than that achieved with the fibula flap, as well as arguably the best donor site cosmesis of all commonly used free flaps in mandible reconstruction, being hidden under clothing. A large amount of bone that tolerates placement of osseointegrated implants can be harvested. In a defect extending across the midline, an osteotomy can be performed to recreate the contour of the anterior mandible. ${ }^{3,54}$ In this instance, it is important that the periosteum and iliacus muscle on the medial surface are kept intact to maintain the blood supply to the distal portion of the iliac crest. The muscle cuff bridging the two segments along the superior margin of the iliac crest must also be kept in continuity. Due to laxity of skin in the area, primary closure of the donor site is often possible.

However, the DCIA flap also has several significant disadvantages, which has prevented it from becoming the gold standard in mandibular reconstruction. Groin skin provides a poor color match in the head and neck. The natural curvature of the iliac crest makes shaping the bone in anterior defects difficult. The obligatory muscle cuff is bulky and difficult to inset, and it results in a poor aesthetic outcome. The bulky soft tissue part of the flap is not easily inset in relation to the bone, as the musculocutaneous perforators to the skin do 
not tolerate shearing and torsion well. This makes resurfacing of intraoral defects difficult as the skin paddle is located on the external aspect of the iliac crest bone. Accessory flaps such as pedicled pectoralis major to reconstruct one surface or a second free flap are options in reconstruction of extensive through-and-through mandibular defects.

As harvest of the DCIA flap involves extensive dissection and division of the oblique and transversalis muscles, there is the risk of postoperative hernia. This can be prevented through meticulous closure of the abdominal wall as detailed by Taylor. ${ }^{55}$ Another complication is injury due to the lateral cutaneous nerve of the thigh and subsequent numbness in that region due to the excessive dissection required. Patients typically have pain at the donor site that limits gait and prevents early mobilization. This may limit the use of the DCIA flap in elderly patients. In general, however, gait disturbance resolves after the initial postoperative period. ${ }^{3}$

In our practice, the DCIA flap is used as a secondline free flap, when the fibula is not available. An example is illustrated in Fig. 3, where the patient had a

A
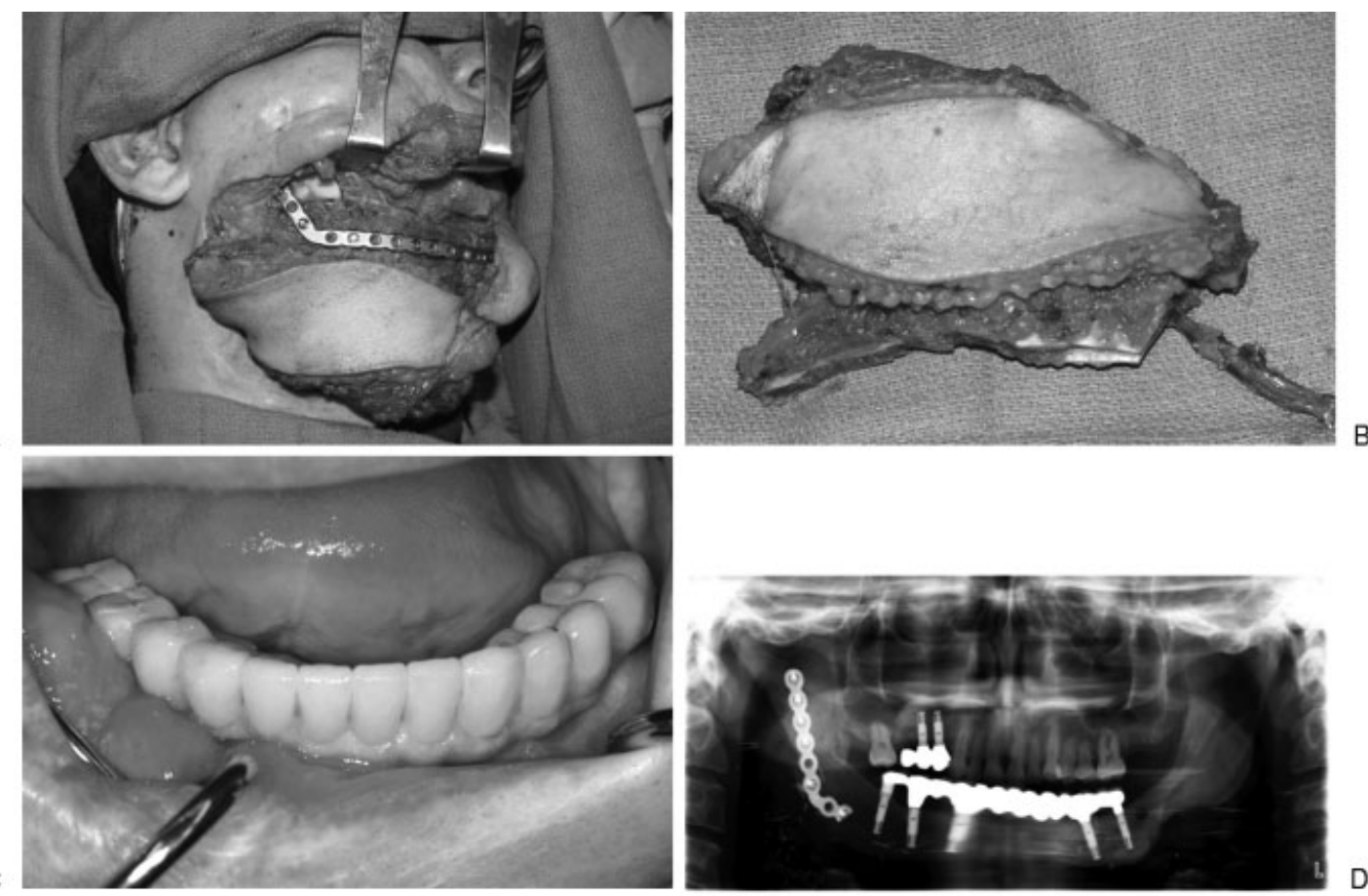

B

C

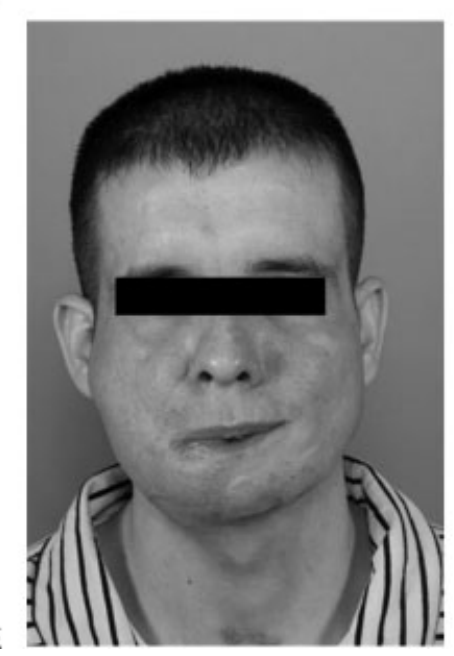

Figure 3 A deep circumflex iliac artery (DCIA) flap was used to reconstruct a large right LC-s mandibular defect, where the fibula and radial forearm were not available due to previous reconstruction. (A) Intraoperative photograph showing the flap inset and held in place with a 2.4-mm reconstruction plate. (B) Harvested iliac crest osteocutaneous flap. (C) Complete dental restoration with osseointegrated implants, 14 months after surgery. (D) Panorex shows union of DCIA flap with native mandible on both sides. Part of the reconstruction plate has been removed to facilitate placement of osseointegrated implants. (E) Frontal view of patient, 14 months after surgery. 
successful reconstruction and ultimately full dental rehabilitation using osseointegrated implants.

\section{Scapular Free Osteocutaneous Flap}

The scapular osteocutaneous free flap is based off the circumflex scapular arterial (CSA) system. It provides an unparalleled quantity of skin and soft tissue and also allows chimeric flaps to be harvested, with multiple skin paddles for reconstruction of complex mandibular defects. When a very large quantity of soft tissue is required, the scapular flap can be harvested together with the latissimus dorsi for additional fill. ${ }^{56}$ Skin paddles can be based off the transverse branch (scapular flap) or vertical branch (parascapular flap) of the circumflex scapular system. Bone is supplied either by perforating vessels from the CSA or the angular branch of the thoracodorsal artery. The lateral border of the scapula provides up to $14 \mathrm{~cm}$ of corticocancellous bone. ${ }^{57}$ The diameter of the vessels is 2 to $3 \mathrm{~mm}$, and pedicle length is 6 to $9 \mathrm{~cm}$.

Unfortunately, bone harvested with the scapular osteocutaneous flap lacks a segmental blood supply and hence does not tolerate osteotomies. A single osteotomy can be made, with two bone segments based off the CSA and angular branch of the thoracodorsal artery. The angular branch can supply as much as $8 \mathrm{~cm}$ of inferior border scapular bone, ${ }^{57}$ and originates 6 to $9 \mathrm{~cm}$ from the bony branch of the CSA. ${ }^{58}$ The quality of scapular bone is, in general, inferior to that obtained with fibula and DCIA flaps; however, a majority of specimens tolerate placement of osseointegrated implants. ${ }^{59}$

Advantages of the scapular flap include a concealed donor site and large quantity of skin and soft tissue. Disadvantages include inability to use a two-team approach as harvest of the flap necessitates turning from the supine to lateral position, as well as decreased range of motion of the shoulder and difficulty lifting objects after surgery. ${ }^{57,60}$ However, in a study by Coleman et $\mathrm{al},{ }^{61}$ symptoms of pain, mobility, and strength were judged as "mild" for most patients, with little to no limitation of activities of daily living.

\section{Radial Forearm Osteocutaneous Flap}

The radial forearm flap provides a large quantity of soft, supple tissue that finds many applications in reconstruction of the head and neck. As an osteocutaneous flap, however, it is limited in that only a short segment of thin monocortical bone measuring up to $14 \mathrm{~cm}$ can be harvested and does not tolerate osteotomies well. Bone harvest should be limited to $30 \%$ of the circumference to prevent subsequent fracture of the radius. ${ }^{62}$ Success of single and double osteotomies using radial bone, however, has been reported for mandible reconstruction. ${ }^{63}$ To preserve viability of the bone, it must be harvested in continuity with a cuff of flexor pollicis longus to preserve perfusion from branches through the lateral intermuscular septum from the radial artery. Because of its limited thickness, radial bone supports osseointegrated implant placement poorly. ${ }^{64}$

The main criticism of the radial forearm osteocutaneous flap is the incidence of fracture of the radius after flap harvest, which, in the literature, has ranged from 0 to $67 \% .{ }^{62-65}$ Methods to prevent this include use of a keel-shaped osteotomy, ${ }^{62}$ prophylactic plating ${ }^{66}$ of the radius, bone grafting of the donor, and preventing overzealous bone harvest. Other limitations include an unsightly donor site as well as requirement for a volar splint or cast if a split-thickness skin graft is used to aid in closure of the donor site.

Prefabricated radial forearm flaps have recently been reported for mandibular reconstruction, circumventing the problem of inadequate bone stock. Leonhardt et $\mathrm{al}^{67}$ reported implantation of cylinders of cancellous iliac crest, with elevation and transfer of the flap 4 weeks later. Bone consolidation was observed 4 years after surgery.

\section{OSSEOINTEGRATED IMPLANTS}

Dental rehabilitation is an important part of mandible reconstruction. The use of osseointegrated implants allows stable anchorage for placement of implant-borne dentures, even in the absence of an alveolar ridge, allowing restoration of speech and mastication and enhancing dental cosmesis. The reported incidence of use of osseointegrated implants ranges from 0 to $40 \%{ }^{68,69}$

Implants can be placed at the time of the primary reconstruction or secondarily with a delayed procedure. Advantages of primary implant placement include enhanced access to the bone segment and increased surgical exposure, allowing accurate alignment of implants with the opposing maxillary dentition. Primary placement also avoids the need for a second surgery, enhancing the speed of dental rehabilitation and social adjustment. ${ }^{70}$ This is generally reserved for patients with benign lesions or lowgrade malignant tumors with excellent prognoses.

Delayed placement of osseointegrated implants is favored by others, who suggest that blood supply of the bone flap at the primary surgery may be compromised because of osteotomies and hardware placement, and also that placement of implants is less precise at the first surgery, as healing of the soft tissues and bone has not yet occurred. Also in patients with an unknown prognosis, it may not be appropriate to place implants primarily. ${ }^{68}$

The placement of implants before and after radiotherapy has been advocated by different authors. As there is typically a delay of $\sim 6$ weeks between reconstruction and radiation therapy, and a further delay before onset of the effects of radiation on bone, Urken has argued that primary placement allows osseointegration in the interim period. ${ }^{71}$ However, other reports 
suggest that postoperative radiation increases the risk of loosening of fixtures and development of secondary osteoradionecrosis. ${ }^{72,73}$ Placement of implants after radiotherapy prevents wasting of implants in patients with a poorer prognosis. Implant survival has been reported to be worse in previously irradiated mandibles compared with that for mandibles not exposed to radiation. ${ }^{74,75}$

Prerequisites for placement of osseointegrated implants include an adequate vertical bone height, with different authors quoting values ranging from 5 to $10 \mathrm{~mm} \cdot{ }^{59,68-75} \mathrm{~A}$ minimum of $1 \mathrm{~mm}$ of healthy bone surrounding the implants is also required. ${ }^{76}$

\section{RECENT ADVANCES}

Recent research into mandible reconstruction has focused on the use of tissue engineering approaches to repair bone defects, mostly in large animal models such as swine, goats, and primates. Scaffolds ranging from collagen sponges ${ }^{77}$ to autologous autoclaved bone ${ }^{78}$ have been used together with bone marrow-derived stromal cells and growth factors such as bone morphogenetic protein (BMP) $-2^{77,79}$ to facilitate osteogenic differentiation of implanted cells. BMP-2 has also been used clinically to aid in osseous regeneration of critical-sized mandibular defects with success. ${ }^{80}$ Significantly, a tissue-engineered vascularized bone graft was used successfully to repair an extended mandibular defect in a man. ${ }^{81}$ Three-dimensional CT and computer-aided design techniques were used to create a titanium mesh cage filled with bone blocks and infiltrated with BMP-7. The construct was then implanted into the latissimus dorsi muscle and transferred 7 weeks later as a prefabricated free flap. Such translational advances in basic science research certainly promise better options for reconstruction of the mandible.

\section{CONCLUSION}

Patients requiring mandible reconstruction today have much better outcomes. Vascularized bone flaps are the best option for a functional and aesthetic reconstruction, with the free fibula flap remaining the gold standard for mandible reconstruction. Reconstruction with alternative flaps such as scapula, iliac crest, and radial forearm flaps results in good outcomes in patients in whom fibula flaps are not available. Advances in translational research promise new modalities of treatment.

\section{REFERENCES}

1. Griffin CJ, Hawthorn R, Harris R. Anatomy and histology of the human temporomandibular joint. Monogr Oral Sci $1975 ; 4: 1-26$

2. Miller MJ, Schusterman MA. Secondary deformities following mandibular reconstruction. Clin Plast Surg 1997;24:551-563
3. Jewer DD, Boyd JB, Manktelow RT, et al. Orofacial and mandibular reconstruction with the iliac crest free flap: a review of 60 cases and a new method of classification. Plast Reconstr Surg 1989;84:391-403; discussion 404-405

4. Hidalgo DA, Pusic AL. Free-flap mandibular reconstruction: a 10-year follow-up study. Plast Reconstr Surg 2002;110:438449; discussion 450-451

5. Takushima A, Harii K, Asato H, Nakatsuka T, Kimata Y. Mandibular reconstruction using microvascular free flaps: a statistical analysis of 178 cases. Plast Reconstr Surg 2001;108: 1555-1563

6. Cordeiro PG, Disa JJ, Hidalgo DA, Hu QY. Reconstruction of the mandible with osseous free flaps: a 10-year experience with 150 consecutive patients. Plast Reconstr Surg 1999;104: 1314-1320

7. Anthony JP, Foster RD, Kaplan MJ, Singer MI, Pogrel MA. Fibular free flap reconstruction of the "true" lateral mandibular defect. Ann Plast Surg 1997;38:137-146

8. Wei FC, Celik N, Yang WG, Chen IH, Chang YM, Chen HC. Complications after reconstruction by plate and softtissue free flap in composite mandibular defects and secondary salvage reconstruction with osteocutaneous flap. Plast Reconstr Surg 2003;112:37-42

9. Shpitzer T, Gullane PJ, Neligan PC, et al. The free vascularized flap and the flap plate options: comparative results of reconstruction of lateral mandibular defects. Laryngoscope 2000;110:2056-2060

10. Schusterman MA, Reece GP, Kroll SS, Weldon ME. Use of the AO plate for immediate mandibular reconstruction in cancer patients. Plast Reconstr Surg 1991;88:588-593

11. Blackwell KE, Buchbinder D, Urken ML. Lateral mandibular reconstruction using soft-tissue free flaps and plates. Arch Otolaryngol Head Neck Surg 1996;122:672-678

12. Cordeiro PG, Hidalgo DA. Soft tissue coverage of mandibular reconstruction plates. Head Neck 1994;16:112-115

13. Mariani PB, Kowalski LP, Magrin J. Reconstruction of large defects postmandibulectomy for oral cancer using plates and myocutaneous flaps: a long-term follow-up. Int J Oral Maxillofac Surg 2006;35:427-432

14. Maurer P, Eckert AW, Kriwalsky MS, Schubert J. Scope and limitations of methods of mandibular reconstruction: a long-term follow-up. Br J Oral Maxillofac Surg 2010;48: 100-104

15. van Gemert JT, van Es RJ, Van Cann EM, Koole R. Nonvascularized bone grafts for segmental reconstruction of the mandible—a reappraisal. J Oral Maxillofac Surg 2009;67: 1446-1452

16. Foster RD, Anthony JP, Sharma A, Pogrel MA. Vascularized bone flaps versus nonvascularized bone grafts for mandibular reconstruction: an outcome analysis of primary bony union and endosseous implant success. Head Neck 1999;21:66-71

17. Mosahebi A, Chaudhry A, McCarthy CM, et al. Reconstruction of extensive composite posterolateral mandibular defects using nonosseous free tissue transfer. Plast Reconstr Surg 2009; 124:1571-1577

18. Hanasono MM, Zevallos JP, Skoracki RJ, Yu P. A prospective analysis of bony versus soft tissue reconstruction for posterior mandibular defects. Plast Reconstr Surg 2010; 125:1413-1421

19. King TW, Gallas MT, Robb GL, Lalani Z, Miller MJ. Aesthetic and functional outcomes using osseous or softtissue free flaps. J Reconstr Microsurg 2002;18:365-371 
20. Wei FC, Demirkan F, Chen HC, Chen IH. Double free flaps in reconstruction of extensive composite mandibular defects in head and neck cancer. Plast Reconstr Surg 1999;103:39-47

21. Wei FC, Celik N, Chen HC, Cheng MH, Huang WC. Combined anterolateral thigh flap and vascularized fibula osteoseptocutaneous flap in reconstruction of extensive composite mandibular defects. Plast Reconstr Surg 2002;109: 45-52

22. Chen HC, Demirkan F, Wei FC, Cheng SL, Cheng MH, Chen IH. Free fibula osteoseptocutaneous-pedicled pectoralis major myocutaneous flap combination in reconstruction of extensive composite mandibular defects. Plast Reconstr Surg 1999;103:839-845

23. Deleyiannis FW, Rogers C, Lee E, et al. Reconstruction of the lateral mandibulectomy defect: management based on prognosis and location and volume of soft tissue resection. Laryngoscope 2006;116:2071-2080

24. Deleyiannis FW, Lee E, Gastman B, et al. Prognosis as a determinant of free flap utilization for reconstruction of the lateral mandibular defect. Head Neck 2006;28:1061-1068

25. Urken ML, Buchbinder D, Weinberg H, et al. Functional evaluation following microvascular oromandibular reconstruction of the oral cancer patient: a comparative study of reconstructed and nonreconstructed patients. Laryngoscope 1991;101:935-950

26. Hidalgo DA. Condyle transplantation in free flap mandible reconstruction. Plast Reconstr Surg 1994;93:770-781; discussion 782-783

27. Wax MK, Winslow CP, Hansen J, et al. A retrospective analysis of temporomandibular joint reconstruction with free fibula microvascular flap. Laryngoscope 2000;110:977-981

28. Umeda H, Kaban LB, Pogrel MA, Stern M. Long-term viability of the temporalis muscle/fascia flap used for temporomandibular joint reconstruction. J Oral Maxillofac Surg 1993;51:530-533; discussion 534

29. Güzel MZ, Arslan H, Saraç M. Mandibular condyle reconstruction with inlay application of autogenous costochondral graft after condylectomy: Cerrahpaa's technique. J Oral Maxillofac Surg 2007;65:615-620

30. El-Sayed KM. Temporomandibular joint reconstruction with costochondral graft using modified approach. Int J Oral Maxillofac Surg 2008;37:897-902

31. Kroll SS, Robb GL, Miller MJ, Reese GP, Evans GRD. Reconstruction of posterior mandibular defects with soft tissue using the rectus abdominis free flap. Br J Plast Surg 1998;51:503-507

32. Butler CE, Lewin JS. Reconstruction of large composite oromandibulomaxillary defects with free vertical rectus abdominis myocutaneous flaps. Plast Reconstr Surg 2004; 113:499-507

33. Wei FC, Seah CS, Tsai YC, Liu SJ, Tsai MS. Fibula osteoseptocutaneous flap for reconstruction of composite mandibular defects. Plast Reconstr Surg 1994;93:294-304; discussion 305-306

34. Hidalgo DA, Rekow A. A review of 60 consecutive fibula free flap mandible reconstructions. Plast Reconstr Surg 1995;96:585-596; discussion 597-602

35. Wong CH, Ong YS, Chew KY, Tan BK, Song C. The fibula osteoseptocutaneous flap incorporating the hemisoleus muscle for complex head and neck defects: anatomical study and clinical applications. Plast Reconstr Surg 2009;124: 1956-1964
36. Wong CH, Tan BK, Wei FC, Song C. Use of the soleus musculocutaneous perforator for skin paddle salvage of the fibula osteoseptocutaneous flap: anatomical study and clinical confirmation. Plast Reconstr Surg 2007;120:1576-1584

37. Mojallal A, Besse JL, Breton P. [Donor site morbidity after free fibula flap. Report of 42 consecutive cases]. Ann Chir Plast Esthet 2004;49:3-10

38. O'Leary MJ, Martin PJ, Hayden RE. The neurocutaneous free fibula flap in mandibular reconstruction. Otolaryngol Clin North Am 1994;27:1081-1096

39. Woerdeman LA, Chaplin BJ, Griffioen FM, Bos KE. Sensate osteocutaneous fibula flap: anatomic study of the innervation pattern of the skin flap. Head Neck 1998;20:310-314

40. Anthony JP, Rawnsley JD, Benhaim P, Ritter EF, Sadowsky $\mathrm{SH}$, Singer MI. Donor leg morbidity and function after fibula free flap mandible reconstruction. Plast Reconstr Surg 1995;96:146-152

41. Bodde EW, de Visser E, Duysens JE, Hartman EH. Donorsite morbidity after free vascularized autogenous fibular transfer: subjective and quantitative analyses. Plast Reconstr Surg 2003;111:2237-2242

42. Sassu P, Acland RD, Salgado CJ, Mardini S, Ozyurekoglu T. Anatomy and vascularization of the flexor hallucis longus muscle and its implication in free fibula flap transfer: an anatomical study. Ann Plast Surg 2010;64:233-237

43. Jones NF, Swartz WM, Mears DC, Jupiter JB, Grossman A. The "double barrel" free vascularized fibular bone graft. Plast Reconstr Surg 1988;81:378-385

44. Horiuchi K, Hattori A, Inada I, et al. Mandibular reconstruction using the double barrel fibular graft. Microsurgery 1995;16:450-454

45. Wallace CG, Chang YM, Tsai CY, Wei FC. Harnessing the potential of the free fibula osteoseptocutaneous flap in mandible reconstruction. Plast Reconstr Surg 2010;125: 305-314

46. Iizuka T, Hallermann W, Seto I, Smolka W, Smolka K, Bosshardt DD. Bi-directional distraction osteogenesis of the alveolar bone using an extraosseous device. Clin Oral Implants Res 2005;16:700-707

47. Schleier P, Hyckel P, Fried W, et al. Vertical distraction of fibula transplant in a case of mandibular defect caused by shotgun injury. Int J Oral Maxillofac Surg 2006;35:861-864

48. Blackwell KE. Donor site evaluation for fibula free flap transfer. Am J Otolaryngol 1998;19:89-95

49. Fukaya E, Grossman RF, Saloner D, Leon P, Nozaki M, Mathes SJ. Magnetic resonance angiography for free fibula flap transfer. J Reconstr Microsurg 2007;23:205-211

50. Ribuffo D, Atzeni M, Saba L, et al. Clinical study of peroneal artery perforators with computed tomographic angiography: implications for fibular flap harvest. Surg Radiol Anat 2010;32:329-334

51. Ahmad N, Kordestani R, Panchal J, Lyles J. The role of donor site angiography before mandibular reconstruction utilizing free flap. J Reconstr Microsurg 2007;23:199-204

52. Kelly AM, Cronin P, Hussain HK, Londy FJ, Chepeha DB, Carlos RC. Preoperative MR angiography in free fibula flap transfer for head and neck cancer: clinical application and influence on surgical decision making. AJR Am J Roentgenol 2007;188:268-274

53. Urken ML, Weinberg H, Buchbinder D, et al. Microvascular free flaps in head and neck reconstruction. Report of 200 cases and review of complications. Arch Otolaryngol Head Neck Surg 1994;120:633-640 
54. Boyd JB. The place of the iliac crest in vascularized oromandibular reconstruction. Microsurgery 1994;15: 250-256

55. Taylor GI. Reconstruction of the mandible with free composite iliac bone grafts. Ann Plast Surg 1982;9: 361-376

56. Aviv JE, Urken ML, Vickery C, Weinberg H, Buchbinder D, Biller HF. The combined latissimus dorsi-scapular free flap in head and neck reconstruction. Arch Otolaryngol Head Neck Surg 1991;117:1242-1250

57. Swartz WM, Banis JC, Newton ED, Ramasastry SS, Jones $\mathrm{NF}$, Acland R. The osteocutaneous scapular flap for mandibular and maxillary reconstruction. Plast Reconstr Surg 1986;77:530-545

58. Coleman JJ III, Sultan MR. The bipedicled osteocutaneous scapula flap: a new subscapular system free flap. Plast Reconstr Surg 1991;87:682-692

59. Frodel JL Jr, Funk GF, Capper DT, et al. Osseointegrated implants: a comparative study of bone thickness in four vascularized bone flaps. Plast Reconstr Surg 1993;92:449455; discussion 456-458

60. Sullivan MJ, Carroll WR, Baker SR. The cutaneous scapular free flap in head and neck reconstruction. Arch Otolaryngol Head Neck Surg 1990;116:600-603

61. Coleman SC, Burkey BB, Day TA, et al. Increasing use of the scapula osteocutaneous free flap. Laryngoscope 2000;110: 1419-1424

62. Weinzweig N, Jones NF, Shestak KC, Moon HK, Davies BW. Oromandibular reconstruction using a keel-shaped modification of the radial forearm osteocutaneous flap. Ann Plast Surg 1994;33:359-369; discussion 369-370

63. Thoma A, Allen M, Tadeson BH, Archibald S, Jackson S, Young JE. The fate of the osteotomized free radial forearm osteocutaneous flap in mandible reconstruction. J Reconstr Microsurg 1995;11:215-219

64. Mounsey RA, Boyd JB. Mandibular reconstruction with osseointegrated implants into the free vascularized radius. Plast Reconstr Surg 1994;94:457-464

65. Thoma A, Khadaroo R, Grigenas O, et al. Oromandibular reconstruction with the radial-forearm osteocutaneous flap: experience with 60 consecutive cases. Plast Reconstr Surg 1999;104:368-378; discussion 379-380

66. Kim JH, Rosenthal EL, Ellis T, Wax MK. Radial forearm osteocutaneous free flap in maxillofacial and oromandibular reconstructions. Laryngoscope 2005;115:1697-1701

67. Leonhardt H, Pradel W, Mai R, Markwardt J, Lauer G. Prefabricated bony radial forearm flap for secondary mandible reconstruction after radiochemotherapy. Head Neck 2009;31: 1579-1587

68. Gürlek A, Miller MJ, Jacob RF, Lively JA, Schusterman MA. Functional results of dental restoration with osseointe- grated implants after mandible reconstruction. Plast Reconstr Surg 1998;101:650-655; discussion 656-659

69. Urken ML, Buchbinder D, Costantino PD, et al. Oromandibular reconstruction using microvascular composite flaps: report of 210 cases. Arch Otolaryngol Head Neck Surg 1998; 124:46-55

70. Chang YM, Santamaria E, Wei FC, et al. Primary insertion of osseointegrated dental implants into fibula osteoseptocutaneous free flap for mandible reconstruction. Plast Reconstr Surg 1998;102:680-688

71. Urken ML, Buchbinder D, Weinberg H, Vickery C, Sheiner A, Biller HF. Primary placement of osseointegrated implants in microvascular mandibular reconstruction. Otolaryngol Head Neck Surg 1989;101:56-73

72. Schmelzeisen R, Neukam FW, Shirota T, Specht B, Wichmann M. Postoperative function after implant insertion in vascularized bone grafts in maxilla and mandible. Plast Reconstr Surg 1996;97:719-725

73. Roumanas ED, Markowitz BL, Lorant JA, Calcaterra TC, Jones NF, Beumer J III. Reconstructed mandibular defects: fibula free flaps and osseointegrated implants. Plast Reconstr Surg 1997;99:356-365

74. Teoh KH, Huryn JM, Patel S, et al. Implant prosthodontic rehabilitation of fibula free-flap reconstructed mandibles: a Memorial Sloan-Kettering Cancer Center review of prognostic factors and implant outcomes. Int J Oral Maxillofac Implants 2005;20:738-746

75. Sclaroff A, Haughey B, Gay WD, Paniello R. Immediate mandibular reconstruction and placement of dental implants. At the time of ablative surgery. Oral Surg Oral Med Oral Pathol 1994;78:711-717

76. Kildal M, Wei FC, Chang YM, Chen HC, Chang MH. Mandibular reconstruction with fibula osteoseptocutaneous free flap and osseointegrated dental implants. Clin Plast Surg 2001;28:403-410

77. Seto I, Marukawa E, Asahina I. Mandibular reconstruction using a combination graft of rhBMP-2 with bone marrow cells expanded in vitro. Plast Reconstr Surg 2006;117:902-908

78. von Wilmowsky C, Schwarz S, Kerl JM, et al. Reconstruction of a mandibular defect with autogenous, autoclaved bone grafts and tissue engineering: an in vivo pilot study. J Biomed Mater Res A 2010;93:1510-1518

79. Boyne PJ. Application of bone morphogenetic proteins in the treatment of clinical oral and maxillofacial osseous defects. J Bone Joint Surg Am 2001;83(Pt 2, Suppl 1):S146-S150

80. Herford AS, Boyne PJ. Reconstruction of mandibular continuity defects with bone morphogenetic protein-2 (rhBMP-2). J Oral Maxillofac Surg 2008;66:616-624

81. Warnke PH, Springer IN, Wiltfang J, et al. Growth and transplantation of a custom vascularised bone graft in a man. Lancet 2004;364:766-770 